\title{
Non-Neoplastic Femoral Head Lesions: Magnetic Resonance Imaging Value
}

\author{
REDA A. AL-ARABAWY, M.D.*; ATEF H. TEIMA, M.D.*; OSAMA A. SELIM, M.D.** and \\ MARAM K. EL-GOHARY, M.Sc.* \\ The Departments of Radiodiagnosis \& Medical Imaging* and Orthopedics**, Faculty of Medicine, Tanta University, Egypt
}

\begin{abstract}
Background: Hip pain is a common problem in patients of all ages, attributed to many causes. MRI combined with recent technologic developmentst plays a crucial role in assessment of epiphyseal disorders in great detail without ionizing radiation.

Aim of Study: Was to evaluate the diagnostic value of MRI in assessment of non-neoplastic femoral head lesions.

Patients and Methods: This study included 40 patients, 22 females (55\%) and 18 males (45\%), their ages ranged from 4 to 65 years with a mean age of 35 years complaining of hip pain. The most frequently involved age group was the group $>30-40$ years in both males and females.

All patients were clinically evaluated, and then subjected for radiological examination and medical imaging (MRI) for all patients and ultrasonography for 6 patients ( 5 developmental dysplasia and 1 septic arthritis).

Results: Out of forty patients who had performed MRI were classified to: Avascular necrosis; the commonest disease in our study; as it is seen in $12(30 \%)$ patients, followed by; osteoarthritis in $6(15 \%)$ patients, migratory osteoporosis in $4(10 \%)$ patients, septic arthritis in $4(10 \%)$ patients, developmental dysplasia in $5(12.5 \%)$ patients, Perthe's disease in $4(10 \%)$ patients, slipped capital femoral epiphysis in $3(7.5 \%)$ patients and stress fractures in $2(5 \%)$ patients.

The final diagnosis achieved through the MRI findings were confirmed by surgical data in 6 patients with avascular necrosis, histopathology in 5 patients $(3$ septic arthritis and 2 osteoarthritis) and follow-up by clinical, laboratory and other imaging studies in 29 patients.

Conclusion: MRI is highly sensitive imaging modality for diagnosis and characterizing of different non-neoplastic femoral head lesions and accurate for assessing the full extent of osseous, chondral and soft tissue abnormalities of the hip joint.
\end{abstract}

Key Words: Femoral head lesions - Magnetic resonance imaging.

Correspondence to: Dr. Reda A. Al-Arabawy, The Department of Radiodiagnosis \& Medical Imaging, Faculty of Medicine, Tanta University, Egypt

\section{Introduction}

HIP pain is a common and disabling condition that affects patients of all ages. The differential diagnosis of hip pain is broad, presenting a diagnostic challenge. Magnetic resonance imaging is valuable for the detection of occult traumatic fractures, stress fractures, and osteonecrosis of the femoral head [1].

MRI has become the imaging modality of choice, as it is highly sensitive and specific for osteonecrosis. T1W images on MRI typically demonstrate a serpiginous "band like" lesion with low signal intensity in the anterosuperior femoral head, and a "double-line sign" can be seen on T2 sequences [2].

MR imaging is a valuable tool in the diagnosis of early or radiographically occult Legg-CalvéPerthes disease. It shows the extent of epiphyseal involvement [3].

Occult fractures in the elderly are one of the most frequent indications for MRI of the hip. In these generally osteoporotic patients, plain films may not demonstrate the fracture line, and bone scintigraphy may demonstrate increased uptake only several days after the trauma. MRI is highly sensitive for detecting the fracture and the surrounding edema immediately after the traumatic event [4]

The key MR imaging features of rapidly destructive hip osteoarthritis include an extensive bone marrow edema like pattern in the femoral head and neck, femoral head flattening, and cystlike subchondral defects. Additional findings include epiphyseal low-signal-intensity lines, bandlike areas of low signal intensity in the subchondral bone of the femoral head [5]. 
Transient osteoporosis of the hip is an uncommon cause of hip pain, mostly affecting healthy middle-aged men and also women in the third trimester of pregnancy [6]

MRI of congenital dislocation of the hip has several advantages: It is non-invasive, harmless, painless, and involves no ionizing radiation. MRI also provide anatomical images in several crosssections [7].

The aim of this work was to assess the role of magnetic resonance imaging in diagnosis of nonneoplastic femoral head lesions.

\section{Patients and Methods}

This prospective study was conducted on 40 patients (18 males and 22 females); the age range from 4-65 years with a mean age of about 35 years. The most frequently involved age group was the group > 30-40 in both males and females. Patients presented clinically with different hip joint complaints (hip pain 40, lower back pain 10, limited movement 8, hip joint swelling 4 and constitutional symptoms 2), 25 patients had unilateral affection, and 15 patients had bilateral affection, some of the patients were referred to private radiology centers and others were referred from Orthopedic Surgery, Pediatric, Rheumatology, out-patient clinics and Emergency Hospital at Tanta University Hospital to Radiodiagnosis and Medical Imaging Department for MR examination of the hip for diagnosis and evaluation. This study was performed at the period between July 2016 to August 2017.

The study was performed according to the guidelines of Ethical Committee and was approved by our institutional review board. All patients gave written informed consent to be included in this study.

\section{Inclusion criteria:}

Patients complain of acute and chronic hip joint pain with limited hip movement.

\section{Exclusion criteria:}

- Patients having a heart pacemaker.

- Patients having a metallic foreign bodies or who have an aneurysm clip.

- Patients with severe claustrophobia.

- Patients who have referred pain in their hip joint.

- Known patients of hip joint malignancy.

All the patients were subjected to the following:

- Detailed history taking.
- Local examination of the diseased hip were performed to detect external signs like swelling or inflammation.

- Laboratory investigations including complete blood cell counts, $\mathrm{C}$ reactive protein, erythrocyte sedimentation rate, serological tests for rheumatoid factor.

- Conventional radiography of both hips were performed for all the patients mostly in anteroposterior to detect fractures, dislocations, bony lesions.

- MRI examinations of both hips were performed for all the patients using a 1.5 Tesla MRI machine scanner.

- Ultra-sonography of the affected hip was performed for 6 patients.

\section{Patient preparation:}

Before entering the examination room, the patient was informed about the nature of the examination and the general rules that must be performed.

\section{Protocol of the MRI study:}

Patients were typically positioned supine on the examination table. The feet were internally rotated and gently immobilized with tape if necessary and slight flexion at the knees.

Both hips were examined for suspected bilateral abnormalities using the body coil with a large field of view to determine the extent of the lesions and to allow for comparison between the normal and abnormal sides. The slice thicknesses were adjusted to be $4-8 \mathrm{~mm}$ and thinner slices were used for more details.

Images were taken in the following sequences:

* Scout view of the hip: Coronal TI weighted image was performed for all cases for localization of subsequent slices of different planes and delineate anatomy.

- Coronal T1 and T2 weighted images.

- Axial T1 and T2 weighted images.

- Sagittal TI \& T2 weighted images.

- Coronal STIR (short time inversion recovery) weighted images.

- In selective cases; post contrast TI weighted images in sagittal, axial and coronal planes were performed immediately after intravenous bolus injection of Gadolinium DTPA in dose of 0.1 mmoll/kg. In 7 patients, who were clinically and 
radiologically suspected to have infective arthritis.

\section{Interpretation was done regarding assessment} of the followings:

- Hip joint alignment on both sides to determine femoral head acetabular articulation and exclude femoral head dislocation.

- Femoral heads regarding size, shape and the signal intensity. Femoral head marrow signal intensity was estimated in both T1 \& T2WIs and graded as normal, increased or decreased (judged relative to the contro-lateral femoral head in unilateral disease or to the subcutaneous fat and greater trochanteric epiphysis in bilateral diseases). The femoral epiphysis is divided into threecompartment (medial, lateral and central) for localization of the abnormal signals.

- The joint space for presence or absence of joint effusion and is graded into mild, moderate and severe and for presence of any intra-articular loose bodies.

- The joint synovium to determine the degree of synovial thickening and the degree of enhancement after contrast study or any abnormal signal in the synovium in all pulse sequences.

- The pelvic bones and the upper femur, for exclusion of any bone fractures, tumors and infection and assess the signal intensity of the bone marrow and evaluate any abnormal signal in all pulse sequences.

- The periarticular soft tissues for any abnormal signal or swelling.

- The surrounding muscles and intra-pelvic soft tissue structures for the presence of any abnormal signal for exclusion of muscle tear or strain or other inflammatory or neoplastaic lesions.

- The findings obtained by MRI were recorded and compared with the final diagnosis achieved by surgical data in 7 patients(core decompression $\&$ total hip arthroplasty), culture and sensitivity of the aspirated joint effusion in 5 patients, histopathology in 5 patients and follow-up by clinical, laboratory and other imaging studies in 23 patients.

- The sensitivity of the MRI in diagnosis of the different hip joint pathologies was calculated according to the following formula:

$$
\text { Sensitivity }=\frac{\text { True positive }}{\text { True positive }+ \text { false negative }} \times 100
$$

\section{Results}

This study included 40 patients (18 males and 22 females) presented clinically with different hip joint complaints.

Out of the 40 patients of our study who had performed hip MRI; 12 patients showed avascular necrosis $(30 \%)$ patients, 6 patients with osteoarthritis (15\%), 4 patients with migratory osteoporosis $(10 \%), 4$ patients with septic arthritis $(10 \%), 5$ patients with developmental dysplasia (12.5\%), 4 patients with Perthe's disease (10\%), 3 patients with slipped capital femoral epiphysis $(7.5 \%)$ and 2 patients with stress fractures $(5 \%)$. These data are shown in (Table 1).

Table (1): MRI classification of femoral head lesions of 40 patients of our study.

\begin{tabular}{lcc}
\hline Final diagnosis & No. of patients & $\%$ \\
\hline Avascular necrosis & 12 & 30 \\
Osteoarthritis & 6 & 15 \\
Migratory osteoporosis & 4 & 10 \\
Septic arthritis & 4 & 10 \\
Developmental dysplasia & 5 & 12.5 \\
Perthes disease & 4 & 10 \\
Slipped capital femoral epiphysis & 3 & 7.5 \\
Stress fractures & 2 & 5 \\
\hline Total & 40 & 100 \\
\hline
\end{tabular}

Out of 40 patients of our study; 6 patients showed bilateral avascular necrosis, 2 patients showed bilateral osteoarthritis, 1 patient showed bilateral migratory osteoporosis, 1 patient showed bilateral septic arthritis, 2 patients showed bilateral developmental dysplasia, 2 patients showed bilateral Perthe's disease and 1 patient showed bilateral slipped capital femoral epiphysis. Both 2 patients with stress fracture are unilateral. $\mathrm{X}^{2} 1.253 \& p$ value 0.939 .

Out of the 40 patients of our study; 12 patients were diagnosed as avascular necrosis through MRI examination, only 10 cases had confirmed to be avascular necrosis (true positive) while the last 2 cases were confirmed to be transient bone marrow edema and subchondral stress fracture of the femoral head (false negative). So, the sensitivity of MRI in diagnosis of avascular necrosis was $83.3 \%$.

12 patients with avascular necrosis were classified into 4 stages according to MRI findings: 1 patient showed stage I, 3 patients with stage II, 5 patients with stage III and 3 patients with stage IV. 
Characteristic MRI findings of avascular necrosis which were depicted; focal subchondral signal abnormality in 9 cases $(75 \%)$, double line sign in 7 cases $(58 \%)$, bone marrow edema in 7 cases (58\%), joint effusion in 3 cases (25\%), subchondral fracture in 3 cases $(25 \%)$ \& osteoarthritis in 2 cases $(17 \%)$.

Out of the 40 patients of our study; 6 patients were diagnosed as osteoarthritis through MRI examination, only 5 cases had confirmed to be osteoarthritis (true positive) while the last 1case was confirmed to be septic arthritis (false negative). So, the sensitivity of MRI in diagnosis of osteoarthritis was $83.3 \%$.

Characteristic MRI findings of osteoarthritis which were depicted; joint effusion in all 6 cases $(100 \%)$, synovial thickening in 5 cases $(83.3 \%)$, bone marrow edema in 4 cases $(66.7 \%)$, subchondral cysts in 2 cases (33.3\%), joint space narrowing in 3 cases (50\%), marginal osteophytes in 4 cases $(66.7 \%) \&$ soft tissue edema in 2 cases $(33.3 \%)$.

Out of the 40 patients of our study; 4 patients were diagnosed as migratory osteoporosis through MRI examination, only 3 cases had confirmed to be migratory osteoporosis (true positive) while the last 1 case was confirmed to be femoral head avascular necrosis (false negative). So, the sensitivity of MRI in diagnosis of migratory osteoporosis was $75 \%$.

Characteristic MRI findings of migratory osteoporosis which were depicted; marrow edema of femoral head and neck in all 4 cases $(100 \%)$, joint effusion in 2 cases $(50 \%)$, marrow edema of the acetabulum in 1 case $(25 \%)$.

Out of the 40 patients of our study; 4 patients were diagnosed as septic arthritis through MRI examination, only 3 cases had confirmed to be septic arthritis (true positive) while the last one case was confirmed to be transient synovitis (false negative). So, the sensitivity of MRI in diagnosis of septic arthritis was $75 \%$.

Characteristic MRI findings of septic arthritis which were depicted; joint effusion in all 4 cases $(100 \%)$, synovial thickening in 3 cases $(75 \%)$, enhanced synovium in 3 case (75\%) and soft tissue edema in 2 cases $(50 \%)$.

Out of the 40 patients of our study; 5 patients were diagnosed as developmental dysplasia of the hip through MRI examination, all 5 cases had confirmed to be developmental dysplasia of the hip (true positive). So, the sensitivity of MRI in diagnosis of developmental dysplasia of the hip was $100 \%$.

Characteristic MRI findings of developmental dysplasia of the hip which were depicted; location of femoral head superior to the acetabulum in all 5 cases $(100 \%)$, irregular shape and shallow acetabulum in 4 cases $(80 \%)$, labral tears in 2 case $(40 \%)$ and degenerative joint disease in 2 cases $(40 \%)$.

Out of the 40 patients of our study; 4 patients were diagnosed as Perthe's disease through MRI examination, only 3 cases had confirmed to be Perthe's disease (true positive) while the last one case was confirmed to be subchondral fissure fracture (false negative). So, the sensitivity of MRI in diagnosis of Perthe's disease was $75 \%$.

Characteristic MRI findings of Perthe's disease which were depicted; femoral epiphyseal distortion (irregular shape, small size \& fragmentation) in all 4 cases $(100 \%)$, abnormal signal intensity of femoral epiphysis in 3 cases (75\%), bone marrow edema in 3 case $(75 \%)$ and joint effusion in 2 cases $(50 \%)$.

Out of the 40 patients of our study; 3 patients were diagnosed as slipped capital femoral epiphysis through MRI examination, only 2 cases had confirmed to be slipped capital femoral epiphysis (true positive) while the last one case was confirmed to be hip subluxation (false negative). So, the sensitivity $66.7 \%$.

Characteristic MRI findings of slipped capital femoral epiphysis which were depicted; flattening and medial displacement of the femoral epiphysis in all 3 cases $(100 \%)$, focal subchondral signal abnormality in 2 cases $(66.7 \%)$, bone marrow edema in 1 case $(33.3 \%)$ and joint effusion in 2 cases $(66.7 \%)$.

Out of the 40 patients of our study; 2 patients were diagnosed as stress fractures through MRI examination, the 2 cases had confirmed to be stress fractures (true positive). So, the sensitivity of MRI in diagnosis of stress fractures was $100 \%$.

Characteristic MRI findings of stress fractures which were depicted; bone marrow edema in all 2 cases $(100 \%)$, femoral head subchondral linear hypointense line in all 2 cases $(100 \%)$, and joint effusion in 1 case $(50 \%)$.

The sensitivity of MRI in the diagnosis of different hip joint lesions according to the true positive and false negative cases is described below in (Table 2). 
Table (2): The sensitivity of the MRI in the diagnosis of different hip joint lesions.

\begin{tabular}{lcccc}
\hline Final diagnosis & $\begin{array}{c}\text { No. of } \\
\text { patients }\end{array}$ & $\begin{array}{c}\text { True } \\
+ \text { ve }\end{array}$ & $\begin{array}{c}\text { False } \\
\text {-ve }\end{array}$ & $\begin{array}{c}\text { Sensi- } \\
\text { tivity }\end{array}$ \\
\hline Avascular necrosis & 12 & 10 & 2 & $83.3 \%$ \\
Osteoarthritis & 6 & 5 & 1 & $83.3 \%$ \\
Migratory osteoporosis & 4 & 3 & 1 & $75 \%$ \\
Septic arthritis & 4 & 3 & 1 & $75 \%$ \\
Developmental dysplasia of the hip & 5 & 5 & 0 & $100 \%$ \\
Perthe's disease & 4 & 3 & 1 & $75 \%$ \\
Slipped capital femoral epiphysis & 3 & 2 & 1 & $66.7 \%$ \\
Stress fractures & 2 & 2 & 0 & $100 \%$ \\
\hline Total & 40 & 33 & 7 & $82.5 \%$ \\
\hline
\end{tabular}

\section{Discussion}

Magnetic Resonance (MR) imaging plays a crucial role in the assessment of epiphyseal disorders by demonstrating cartilaginous and osseous structures in great detail without the use of ionizing radiation. Magnetic Resonance (MR) imaging can be used to evaluate vascularity, marrow, and cartilage and plays a critical role in the assessment of epiphyseal disorders. In cases of hip dysplasia, MR imaging demonstrates un-ossified structures and helps to guide treatment. In cases of trauma, the intra-cartilaginous pathway of fractures and the degree of epiphyseal involvement can be assessed with the use of intravenous gadoliniumbased contrast material, avascular necrosis and reperfusion can be characterized [8]

This study included forty patients, twenty two females (55\%) and eighteen males (45\%), their ages ranged from 4 to 65 years with a mean age of 35 years who underwent MRI hip scan for assessment of complaint. Those 40 patients were classified according to MR findings; 12 patients $(30 \%)$ with avascular necrosis, 6 patients $(15 \%)$ with osteoarthritis, 4 patients $(10 \%)$ with migratory osteoporosis, 4 patients (10\%) with septic arthritis, 5 patients $(12.5 \%)$ with developmental dysplasia, 4 patients (10\%) with Perthe's disease, 3 patients $(7.5 \%)$ with slipped capital femoral epiphysis and 2 patients $(5 \%)$ with stress fractures.

Magnetic Resonance Imaging (MRI) is the most sensitive and specific imaging technique for evaluating avascular necrosis of the femoral head in early/precollapse stage [9].

MRI has several advantages, allows accurate staging by clearly depicting the size of the lesion, it also detects asymptomatic lesions that are undetectable on plain radiographs, thus facilitating early treatment and better response. It provides multi- planar imaging and excellent soft tissue resolution and can demonstrate response of the femoral head to treatment [10]

Out of the 12 patients diagnosed as avascular necrosis, the disease was bilateral in [6] $50 \%$ of patients Fig. (1) and unilateral in the remaining [6] $50 \%$ of patients and this is in agree with Hamilton, T.W. et al. [11] as they reported that it is important to evaluate the contralateral hip, as bilateral involvement has been reported to be between $40 \%$ and $80 \%$.

Manenti et al., [12] reported that (65-85\%) of patients of avascular necrosis, show a characteristic "double line" sign on T2 weighted images which is characterized by an outer low signal of intensity rim with an inner zone of high intensity referred to the granulation tissue, and this is agree with our study that showed the characteristic "double line" sign on T2 weighted images in 9 patients $(75 \%)$.

In our study, the dominant MRI finding was focal subchondral signal abnormality which was identified in all the $12(100 \%)$ patients, followed by the double line sign (serpiginous hypointense line surrounding area of the head with altered marrow signal) that was identified in $9(75 \%)$ patients, bone marrow edema in $6(50 \%)$ patients and joint effusion in $3(25 \%)$ patients.

In our study, the MRI findings of AVN were true positive in 10 patients, false negative in 2 patients and the sensitivity of MRI in diagnosis of avascular necrosis was $83.3 \%$ and this is in agree with Glickstein MF et al., [13] as they reported that MRI is the most sensitive modality in diagnosing AVN, with a sensitivity of $71-100 \%$ and specificity of $94-100 \%$.

There are many classification systems that describe the clinical and radiological severity/ progression of AVN. Ficat and Arlet-staging system is still one of the most commonly used systems. It is based on radiological findings, but does not consider the extent of necrosis. Steinberg et al., [14] added quantification of femoral head involvement to the classification system, but could not gain wide popularity as it was difficult to apply. The Association Research Circulation Osseous (ARCO) system of classification incorporated features of both Ficat and Arlet system and the Steinberg classification [15]

The 12 cases of our study who had avascular necrosis were classified according to degree of affection (1 patient with stage 1 AVN, 3 patients 
with stage 2, 5 patients with stage 3 and 3 patients with stage 4).

Osteoarthritis (OA) is a heterogeneous and multifactorial disease characterized by progressive loss of hyaline articular cartilage and development of altered joint harmony, subchondral sclerosis, intraosseous cysts, and osteophytes. Hip OA is a crippling disease and a major public health problem [16].

Teichtahl et al., [17] suggest that structural MRI abnormalities are present prior to clinical hip OA, and that cartilage defects and Bone Marrow Lesions (BMLs) in the anterior and central superolateral regions identify early structural changes of hip OA and may be potential therapeutic targets for the prevention and early treatment of hip OA.

Hayashi et al., [18] reviewed that subchondral bone marrow lesions are a common imaging feature of OA with clinical significance and typical signal alteration patterns.

The hip is frequently involved in acute inflammatory disorders such as rheumatoid arthritis, seronegative spondyloarthropathies, and juvenile idiopathic arthritis. Conventional radiography is still the mainstay for diagnosis of hip joint damage and subsequent follow-up, but it is now recognized that Magnetic Resonance (MR) imaging is very sensitive imaging method for the detection of articular and paraarticular involvement [19] .

Once joint space narrowing is recognized, the presence of bone erosions suggests an inflammatory arthritis, while osteophytes indicate a degenerative arthritis. The joint distribution and the presence of bone proliferation allow distinction between septic arthritis, rheumatoid arthritis, and the seronegative spondyloarthropathies [20]

Bony erosions are seen well using MRI in early rheumatoid arthritis and are frequently detected before they appear on plain radiographs. Bone marrow oedema \& joint effusion are important MRI features associated with inflammatory joint disease. Synovial membrane inflammation and hypertrophy are detected after contrast enhancement

MRI is able to visualize synovium located deep within joints such as the hip without being obscured by bony structures. Contrast enhanced MRI generally improves tissue visualization \& clearly differentiates inflamed synovium from joint effusion
In this study joint effusion was identified in all the $6(100 \%)$ patients with osteoarthritis, synovial thickening was identified in $5(83.3 \%)$ patients, bone marrow edema in $4(66.7 \%)$ patients, subchondral cysts in $2(33.3 \%)$ patients, joint space narrowing in $3(50 \%)$ patients, marginal osteophytes in $4(66.7 \%)$ patients and soft tissue edema in 2 $(33.3 \%)$ patients, and the sensitivity of MRI in diagnosis of osteoarthritis was $83.3 \%$.

Transient osteoporosis of the hip (TOH) is a rare self-limiting condition that typically affects middle-aged men or, less commonly, women in the third trimester of pregnancy. These individuals present without a history of major trauma but usually developed an acute onset of hip pain accompanied by decreased ranges of motion, and a limping gait [23] .

MRI is the most sensitive and specific imaging technique for detecting transient osteoporosis. MRI shows decreased signal intensity of bone marrow on T1-images and increased signal intensity relative to the intensity of normal marrow on T2-images. Joint effusions are seen on T2-images [24].

Marrow edema of femoral head and neck was identified in MRI scan in all the $4(100 \%)$ patients, as diffuse low signal on T1 weighted images and high signal on T2 and STIR weighted images.

MRI helps to distinguish TOH from other conditions that include avascular necrosis, cancer, stress fracture of neck of femur, septic arthritis, soft tissue injury, radiculopathy, infiltrative marrow process and inflammatory joint diseases [25].

Balakrishnan et al., [26] reported that MRI shows a diffuse edema pattern common to both AVN \& TOH, but the absence of focal defects and subchondral changes is highly suggestive of $\mathrm{TOH}$.

In our study, out of 4 patients who were diagnosed as migratory osteoporosis, MRI findings were true positive in 3 patients. The diagnosis was confirmed by clinical and follow-up MRI scans after conservative treatment and the disease was self-limited, there was 1 false negative patient misdiagnosed as migratory osteoporosis by initial MRI and on follow-up after one month, MRI revealed femoral head avascular necrosis. So, the sensitivity of MRI in diagnosis of migratory osteoporosis was $75 \%$.

Septic arthritis is a common disabling disease that requires early diagnosis for optimal outcome. Any delay in diagnosis of septic arthritis may increase morbidity and lead to complications such 
as bone and cartilage destruction, osteonecrosis, secondary osteoarthritis, osteomyelitis, and eventually ankylosis [27]

In our study, the dominant MRI finding was joint effusion which was identified in all the 4 (100\%) patients, followed by synovial thickening that was identified in $3(75 \%)$ patients, enhanced synovium in $3(75 \%)$ patients and soft tissue edema in $2(50 \%)$ patients.

Synovial inflammation and effusions are readily demonstrated with MR imaging using T2 or inversion recovery sequences and are the earliest finding in septic arthritis. The superior soft tissue resolution of MR imaging clearly demonstrates the distribution of fluid in the joint space, associated bursa, and synovial cyst formation. Involvement of surrounding muscle and tendons, as well as abscess and sinus tract formation are well delineated [28]

In our study, out of the 4 patients who were diagnosed as, septic arthritis. MRI findings were true positive in 3 patients. The diagnosis was confirmed by clinical and laboratory investigations, (ESR, CRP \& TLC) and ultrasound examination confirming the presence of joint effusion. One false negative patient misdiagnosed as septic arthritis, there was no evidence of infection and on follow-up clinically and by ultrasound was diagnosed as transient synovitis. So, the sensitivity of MRI in diagnosis of septic arthritis was $75 \%$.

Developmental dysplasia of the hip is the most common cause of an unstable hip in pediatric population. Left hip is more commonly involved (40 to $60 \%$ of cases) with bilateral involvement in $20 \%$. Magnetic Resonance Imaging (MRI) plays an important role in the early detection as well as in the evaluation of various soft tissue obstacles that can cause hindrance in reduction. Pre-operative MR imaging also helps in determining the acetabular labral coverage which further guides the orthopaedic surgeon in planning the management [28].

MR imaging has numerous advantages over radiography particularly in looking for the ossified femoral nucleus as well as in better demonstration of morphology of the acetabular dysplasia in single examination with lack of ionizing radiation. Also with the proper use of sequences, arthrogram like image can be produced. MR is also used to detect the immediate and delayed post-operative complications [29].

Out of the 5 patients diagnosed as developmental dysplasia of the hip, MRI findings were true positive in all 5 patients Fig. (4). The diagnosis was confirmed by complementary X-ray and US examination of the affected hip and follow-up by clinical and radiological assessment after treatment. So, the sensitivity of MRI in diagnosis of DDH was $100 \%$.

In our study, the dominant MRI finding was location of femoral head superior to the acetabulum which was identified in all the $5(100 \%)$ patients, followed by irregular shape and shallow acetabulum in $4(80 \%)$ patients, labral tears in $2(40 \%)$ patients and degenerative joint disease in $2(40 \%)$ patients.

Legg-Calvé-Perthes Disease (LCPD) is idiopathic osteonecrosis (osteochondrosis) of the immature capital femoral epiphysis. It occurs in as many as $0.016 \%$ of children 2-14 years old, with a peak incidence at 5-6 years old. Boys are 5 times as likely as girls to be affected, and $85-90 \%$ of cases are unilateral. Presenting symptoms include limp and pain in the hip, thigh, or knee [30]

The role of MR imaging in the evaluation of Legg-Calvé-Perthes disease varies according to the severity and duration of the disease. In early LCPD, when in early stage radiographs are normal, the role of MR imaging is to detect the presence of ischemic marrow. In more advanced LCPD, MR imaging can demonstrate the extent of marrow involvement, the degree of cartilaginous or synovial hypertrophy, and the extent of epiphyseal and metaphyseal cartilaginous abnormalities [31]

MR imaging of LCPD has been shown to be more accurate in evaluating the extent of epiphyseal necrosis and can be used to stage the hip and identify when the revascularization period begins. Post-contrast images accurately indicate the viable bone, which should enhance brightly post-contrast. Early enhancement of the lateral pillar (the lateral one third of the femoral head) is consistent with a better prognosis [32].

In our study, out of the 4 patients who were diagnosed as Perthe's disease, Fig. (3) MRI findings were true positive in 3 patients. However, there was 1 false negative patient misdiagnosed as Perthe's disease by MRI but follow-up by another MRI and X-ray studies revealed that there was just marrow edema \& subchondral fissure fracture. So, the sensitivity of MRI in diagnosis of Perthe's disease was $75 \%$.

Two MRI features predicting extensive epiphyseal necrosis were: The first is area of decreased signal intensity on both T1W and T2W images covering over two thirds of the epiphysis and the 
second is diffuse bone marrow oedema of the femoral neck and metaphysis [33]. This goes with our study in which dominant MRI finding was femoral epiphyseal distortion (irregular shape, small size and fragmentation) which was identified in all the $4(100 \%)$ patients, followed by abnormal signal intensity of femoral epiphysis in $3(75 \%)$ patients, bone marrow edema in $3(75 \%)$ patients and joint effusion in $2(50 \%)$ patients.

MRI can be used to depict and characterize several of the most important complications of Legg-Calvé-Perthes Disease. Although it is estimated that approximately $60-70 \%$ of hips affected by LCP disease heal spontaneously without functional impairment at maturity, a considerable number of affected hips become painful later in life, with many eventually requiring arthroplasty [34].

Premature degeneration (secondary osteoarthrosis) of the hip joint is far and away the most common complication observed in healed Legg-CalvéPerthes disease. Abnormal contour of the femoral head leads to repulsion between articular cartilage surfaces, promoting premature degeneration. Premature hip joint degenerative changes may be observed as early as the second or third decades of life in individuals affected by Legg-CalvéPerthes disease and are well depicted by MRI. MRI findings include abnormal joint space narrowing, with thinning of femoral head and acetabular articular cartilage as well as subchondral cyst (geode) and osteophyte formation [34] .

Slipped Capital Femoral Epiphysis (SCFE) is a typical disease of puberty with a reported prevalence of up to 10 per 100,000 . Although it's etiology is unknown, the condition may be associated with biomechanical factors, such as obesity, increased femoral retroversion, and increased physeal obliquity, or with endocrine disorders such as hypothyroidism and hypogonadism [35]

The most frequent presenting complaints are pain in the affected hip, groin, thigh or knee, alteration in hip range of motion and often a gait abnormality. Symptoms may be very mild, even allowing patients to be active and play sports, or so severe that it prevents joint movements [36].

The diagnosis of SCFE can also be difficult. Some patients may present without a limp and may complain of a pain in the knee rather than the hip. Delay in diagnosis of SCFE is a common problem, in some series when the patient's chief complaint is knee pain the missed diagnosis rate is $100 \%$ [37]
Morphologic distortion of the physis, bone marrow edema within the metaphysis and epiphysis, and joint effusion were the pre-operative MRI findings of SCFE. MRI also allows for accurate evaluation of the femoral head vascularization before and after surgery in children with SCFE

In our study, out of the 3 patients diagnosed as slipped capital femoral epiphysis Fig. (2), MRI findings were true positive in 2 patients. However, there was 1 false negative patient misdiagnosed as slipped femoral capital epiphysis \& it was proven to be hip sub-luxation. So, the sensitivity of MRI in diagnosis of slipped femoral capital epiphysis was $66.7 \%$.

Dillon et al., [123] reported that MRI provides an early and sensitive method for detecting the pre-slip stage of the proximal femoral epiphysis and the earliest evidence of slipped capital femoral epiphysis on MRI is diffuse or globular epiphyseal widening and hyperintense signal of the bone marrow along the epiphysis on T2-weighted images which indicate stress and edema. This goes with our study which shows that the dominant MRI finding was widening and displacement of the femoral epiphysis which was identified in all the $3(100 \%)$ patients, followed by focal subchondral signal abnormality that was identified in $2(66.7 \%)$ patients, bone marrow edema in $1(33.3 \%)$ patient and joint effusion in $2(66.7 \%)$ patients.

Subchondral stress fracture of the femoral head has been attributed to insufficiency fracture associated with poor bone quality in the elderly population or as a fatigue fracture in young military recruits. When it occurs in young military recruits, it is usually secondary to increased activity levels

Subchondral Insufficiency Fracture of the Femoral Head (SIFFH) is typically seen in the anterosuperior portion of the femoral head corresponding to the weight bearing surface [40].

SIFFH is characterized by acute onset hip pain, without over trauma that often progressively worsens over time. SIFFH may be associated with joint space narrowing, either at the onset in the setting of an arthritic hip, or with progressive subchondral collapse related to the fracture insult [41].

There are often no apparent lesions to the femoral head on plain radiography. Diagnosis with T1weighted Magnetic Resonance Image (MRI) is made by identification of an irregularly shaped, 
low-intensity band parallel to the subchondral bone, often with associated bone marrow edema [41].

Ikemura S. et al., [42] suggest that the shape of the low-intensity band on MRI is useful for the differentiating subchondral insufficiency fracture from osteonecrosis. In subchondral insufficiency fracture the band is generally irregular, serpiginous, convex to the articular surface, and often discontinuous. In contrast, in osteonecrosis, the lowintensity band is generally smooth and circum-
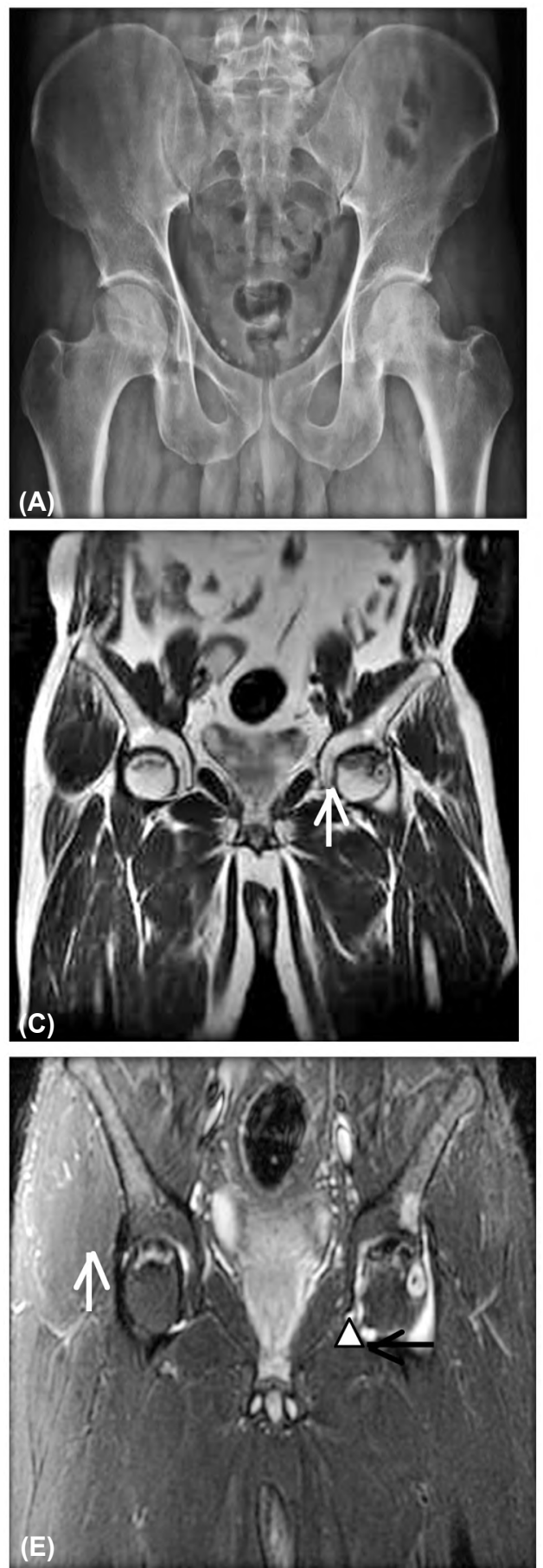

scribes all of the necrotic segments, with concavity to the articular surface.

In our study, out of the 2 patients diagnosed as stress fractures, MRI findings were true positive in the 2 patients and the dominant MRI finding in patients with subchondral stress fractures was bone marrow edema in the $2(100 \%)$ patients, also femoral head subchondral linear hypointense line in the $2(100 \%)$ patients and joint effusion in $1(50 \%)$ patient. So, the sensitivity of MRI in diagnosis of stress fractures was $100 \%$.
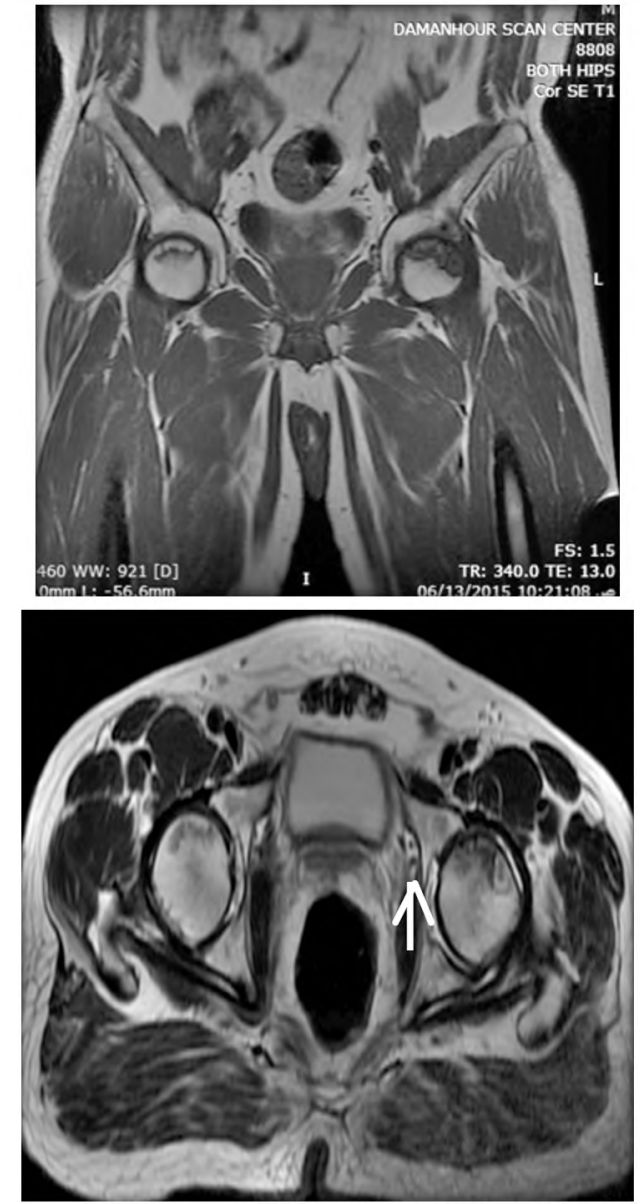

Fig. (1): (A-E): A male patient aged 47 years with bilateral avascular necrosis of femoral head stage 2 on the right side and stage 3 on the left side. Presented clinically by left hip pain with history of long exposure to radiation therapy for colonic cancer. (A) Plain Xray of both hips (A.P.V.) revealed: Relative sclerosis of left femoral head. (B, C \& D) MR T1WI \& T2WI (coronal sections) \& T2WI (axial section) of both hips revealed: Subchondral serpiginous heterogeneous low signal intensity of both femoral heads at T1WI \& low to intermediate signal intensity at T2WI more evident on the left side with hyperintense cystic lesion (white arrows). (E) MR T2WI (coronal section with fat suppression) of both hips revealed: Subchondral serpiginous heterogeneous hyperintense areas at both femoral heads with bilateral "double-line sign" (white arrow), hyperintense cystic formation is seen in left head (arrowhead) and bilateral joint effusion more at left side (black arrow). 

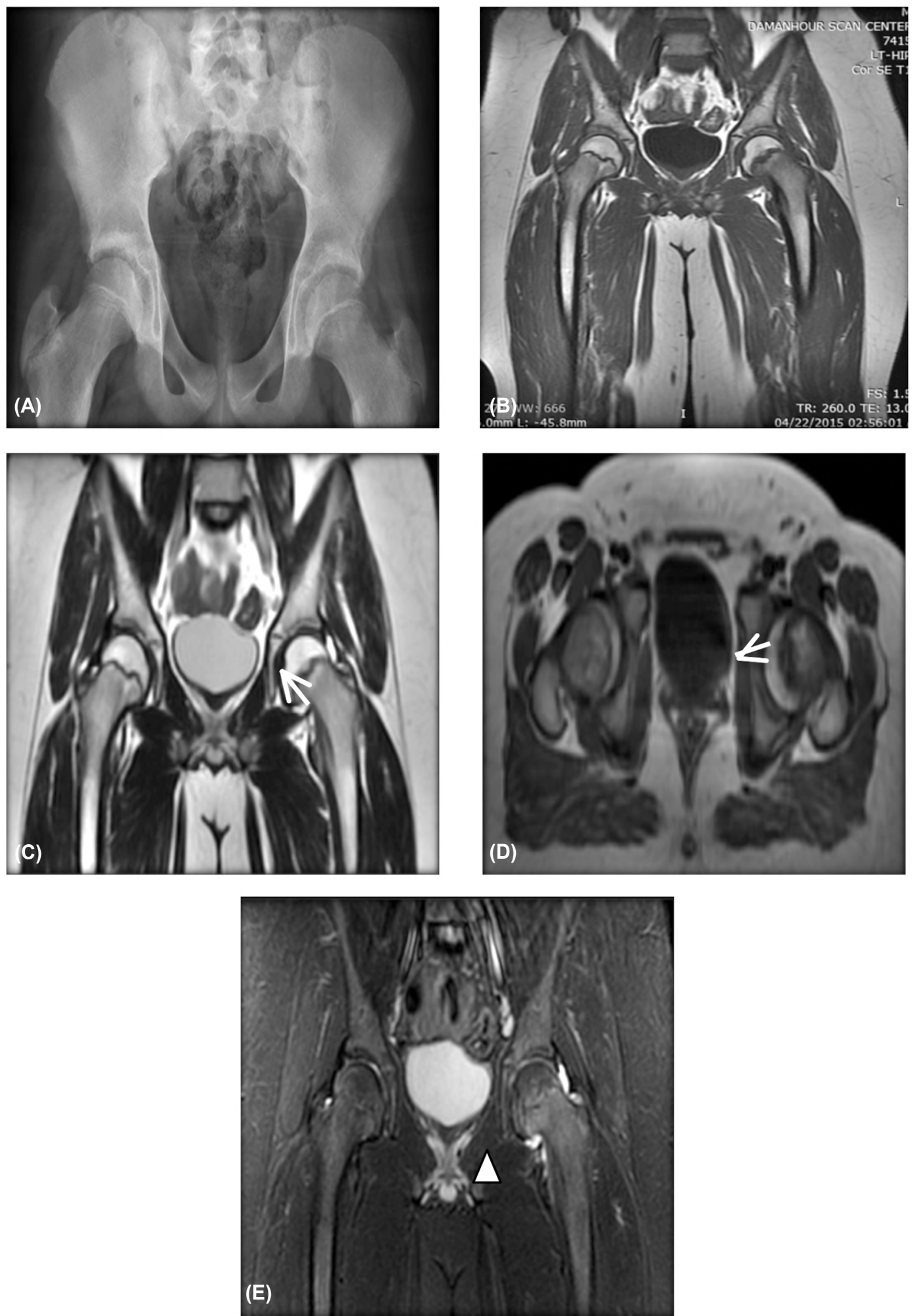

Fig. (2): (A-E): A male patient aged 13 years with left side slipped capital femoral epiphysis. Presented clinically by left hip complaint. (A) Plain X-ray of both hips (A.P.V.) revealed: Flattening and minimal malalignment of the left capital femoral epiphysis compared to the normal right hip. (B, C \& D) MR T1WI \& T2WI (coronal sections) \& T1WI (axial section) of both hips revealed: Diffuse flattening with minimal slippage of the left femoral epiphysis medially (white arrows) \& mild left joint effusion. (E) MR T2WI (coronal section with fat suppression) of both hips revealed: Early left metaphyseal edema in comparison to right side \& mild left joint effusion (arrowhead). 

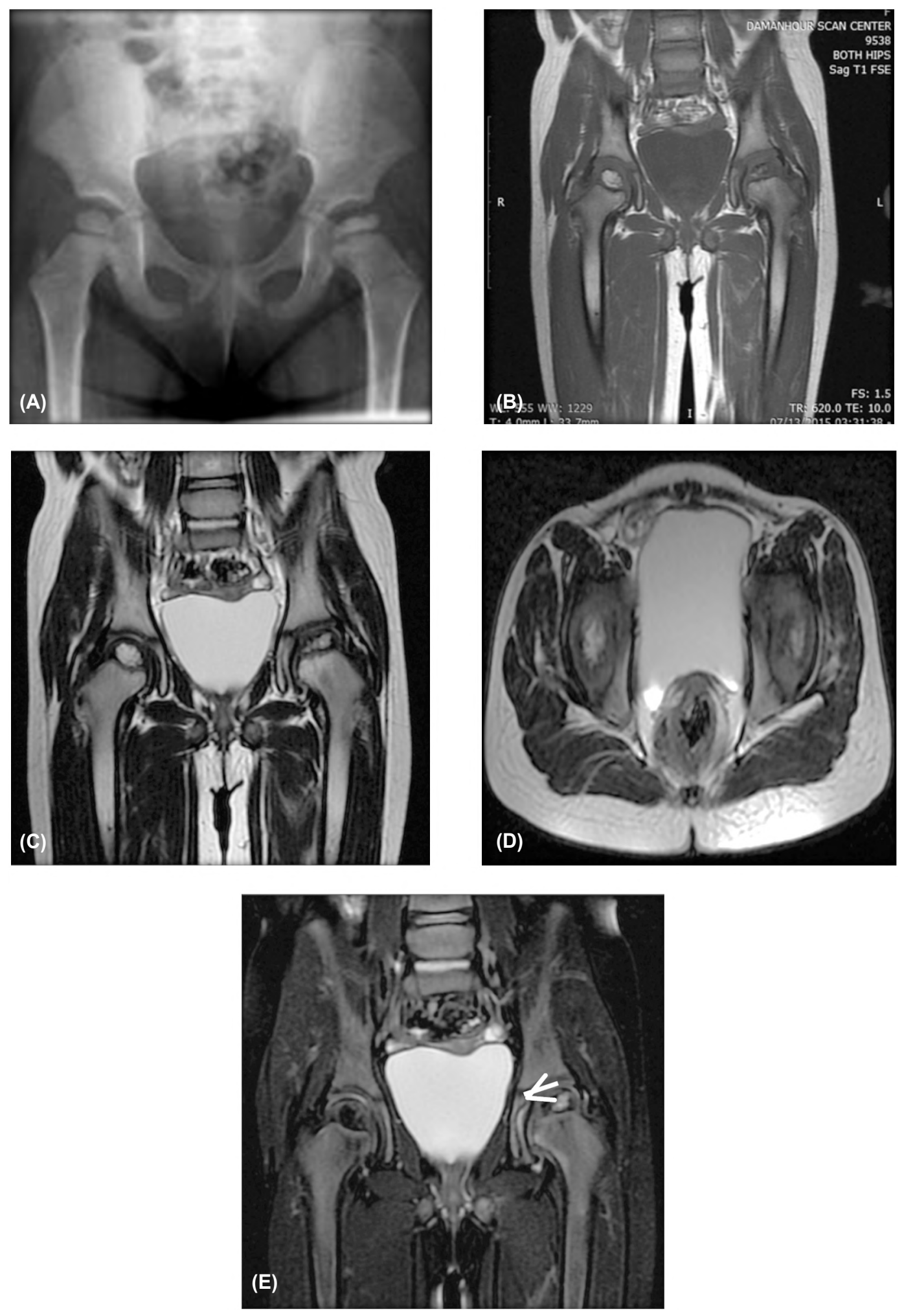

Fig. (3): (A-E): A female child patient aged 4 years with Legg-Calve-Perthes disease of left hip joint. Presented clinically by bilateral hip pain more on the left side. (A) Plain X-ray both hips (A.P.V.) revealed: Flattening and sclerosis of left femoral epiphysis with fragmentation and widening of the joint space on the left side. (B, C \& D) MR T1WI \& T2WI (coronal sections) \& T2WI (axial section) of both hips revealed: Significant loss of epiphyseal height (flattening) with irregular contour of left femoral capital epiphysis that shows low signal intensity in T1WI \& heterogeneous mainly low signal in T2WI in comparison to healthy side due to sclerosis. (E) MR T2WI (coronal section with fat suppression) of both hips revealed: Collapsed left femoral epiphysis with high signal intensity area (fluid) within (white arrow) \& mild joint effusion in left hip joint. 

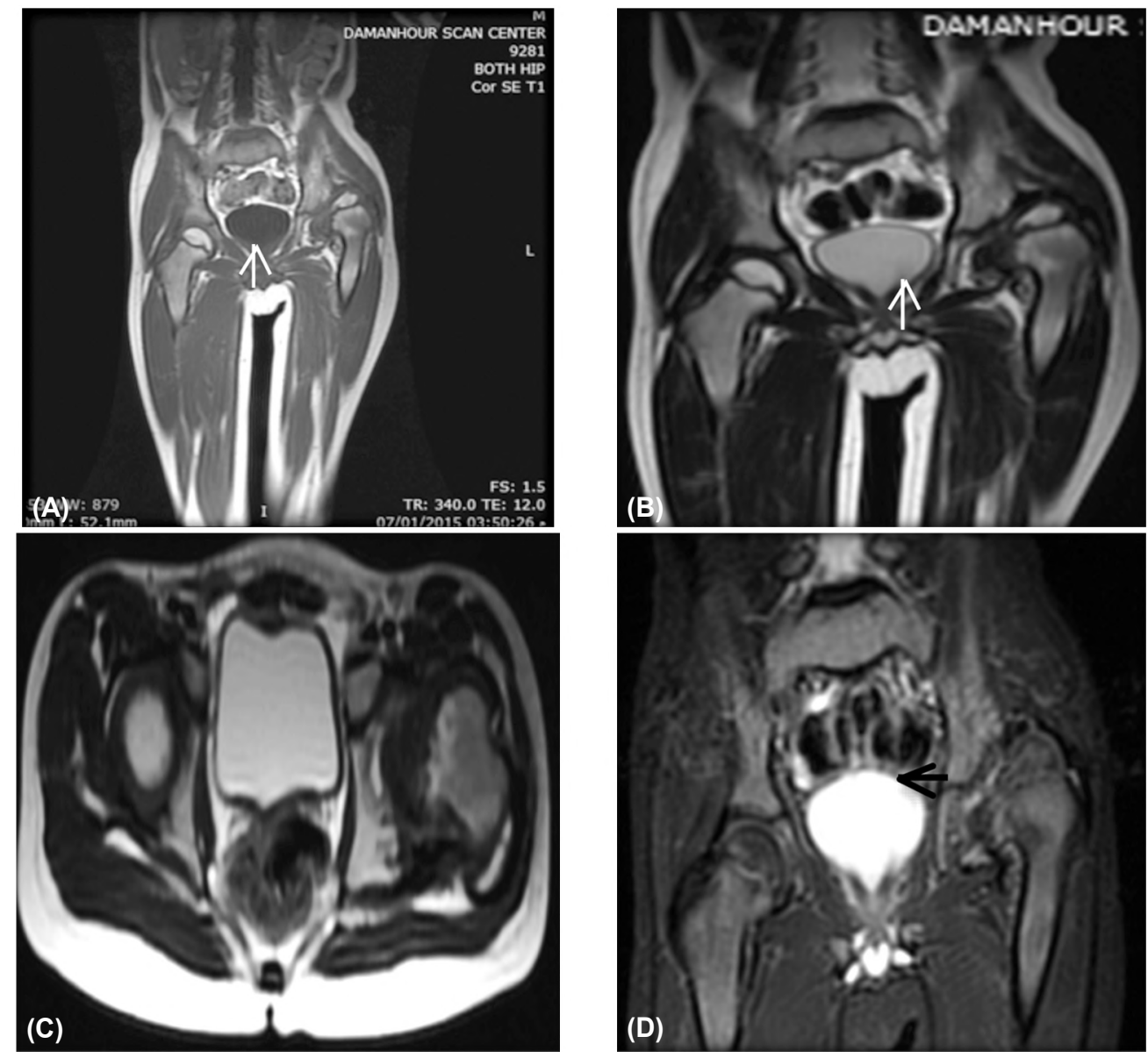

Fig. (4): (A-D): A male patient aged 5 years with left hip dislocation with end arthritic changes.presented clinically by chronic left hip pain, limitation of movements \& swelling. (A, B \& C) MR T1WI \& T2W1 (coronal sections) \& T2W1 (axial section) of both hips revealed: Superolateral displacement of left femoral head from its normal articulation, early flattening \& hypoplasia of femoral head with fine irregularities, hyperintense hypertrophied acetabular labrum (white arrows). (D) T2WI (coronal section with fat suppression) of both hips revealed: Femoral head is displaced superolateral with shallow acetabulum (black arrow).

\section{Conclusion:}

Magnetic resonance imaging is the diagnostic modality of choice, with superior contrast resolution and without harmful radiation, for early diagnosis of most disorders of the hip where radiographic findings are inconclusive. MRI plays a crucial role in assessing and staging the different femoral head lesions to influence therapeutic decisions as it helps the surgeon not only to understand the underlying pathology but also to make the critical decision regarding surgical intervention.

\section{References}

1- WILSON J.J. and FURUKAWA M.: Evaluation of the patient with hip pain. Am. Fam. Physician, 89 (1): 27-34, 2014.

2- KAUSHIK A.P., DAS A. and CUI Q.: Osteonecrosis of the femoral head: An update in year 2012. World Journal of Orthopedics, 3 (5): 49-57, 2012.

3- WEISHAUPT D., EXNER G., HILfiKER P., et al.: Dynamic MR Imaging of the Hip in Legg-Calvé-Perthes
Disease: Comparison with Arthrography. In A.J.R., 174: 1635-37, 2000.

4- BELTRAN J., PATNANA M., BELTRAN L., et al.: MRI of the hip. In Applied Radiology, 33-9, 2002.

5- BOUTRY N., PAUL C., LEROY X., et al.: Rapidly destructive osteoarthritis of the hip: MR imaging findings. A.J.R. Am. J. Roentgenol., 179: 657-63, 2002.

6- McWALTER P. and HASSAN A.: Transient osteoporosis of the hip. Annals of Saudi Medicine, 29 (2): 146-8, 2009.

7- BOS C.F., BLOEM J.L., OBERMANN W.R., et al.: Magnetic resonance imaging in congenital dislocation of the hip. J. Bone Joint Surg., 70: 174-8, 1988.

8- JAIMES C., CHAUVIN N.A., DELGADO J., et al.: MR imaging of normal epiphyseal development and common epiphyseal disorders. Radiographics, 34 (2): 449-71, 2014.

9- NORI M., MARUPAKA S.K., ALLURI S., et al.: MRI Evaluation of Post Core Decompression Changes in Avascular Necrosis of Hip. Journal of Clinical and Diagnostic Research, 9 (12): pp. 4-8, 2015.

10- HORIA B., VALENTIN C. and MIHAELA D.: Avascular necrosis of the femoral head. Journal of Clinical Medicine, Volume 4, No. 1: 26-34, 2009. 
11- HAMILTON T.W., GOODMAN S.M. and FIGGIE M. SAS Weekly Rounds: Avascular Necrosis. H.S.S. Journal, 5 (2): 99-113, 2009.

12- MANENTI G., ALTOBELLI S., PUGLIESE L., et al.: The role of imaging in diagnosis and management of femoral head avascular necrosis. Clinical Cases in Mineral and Bone Metabolism, 12 (Suppl. 1), 31-8, 2015.

13- GLICKSTEIN M.F., BURK D.L., SCHIEBLER M.L., et al.: Avascular necrosis versus other diseases of the hip: Sensitivity of MR imaging. Radiology, 169 (1): 213-5, 1988.

14- STEINBERG M.E., HAYKEN G.D. and STEINBERG D.R.: A quantitative system for staging avascular necrosis. J. Bone Joint Surg. Br., 77: 34-41, 1995.

15- TRIPATHY S.K., GOYAL T. and SEN R.K.: Management of femoral head osteonecrosis: Current concepts. Indian Journal of Orthopaedics, 49 (1): 28-45, 2015.

16- DORÉ D., De HOOG J., GILES G., et al.: A longitudinal study of the association between dietary factors, serum lipids, and bone marrow lesions of the knee. Arthritis Research \& Therapy, 14 (1): R13, 2012.

17- TEICHTAHL A.J., WANG Y., SMITH S., et al.: Structural changes of hip osteoarthritis using magnetic resonance imaging. Arthritis Res. Ther., 16 (5): 466, 2014.

18- XU L., HAYASHI D., ROEMER F.W., FELSON D.T., et al.: Magnetic Resonance Imaging of Subchondral Bone Marrow Lesions in Association with Osteoarthritis. Seminars in Arthritis and Rheumatism, 42 (2): 105-18, 2012.

19- BOUTRY N., KHALIL C., JASPART M., et al.: Imaging of the hip in patients with rheumatic disorders. Eur. J. Radiol., 63 (1): 49-58, 2007.

20- JACOBSON J.A., GIRISH G., JIANG Y., et al.: Radiographic evaluation of arthritis: Degenerative joint disease and variations. Radiology, 248 (3): 737-47, 2000.

21-McQUEEN F.M.: Magnetic resonance imaging in early inflammatory arthritis: What is its role? Rheumatology (Oxford), 39 (7): 700-6, 2000.

22- BRAUN H.J. and GOLD G.E.: Diagnosis of Osteoarthritis: Imaging. Bone, 51 (2): 278-88, 2012.

23- VAN W.K., PRITCHARD P. and TAYLOR J.A.: Transient osteoporosis of the hip: A case report. The Journal of the Canadian Chiropractic Association, 57 (2): 116-22, 2013.

24- McWALTER P. and HASSAN A.: Transient osteoporosis of the hip. Annals of Saudi Medicine, 29 (2): 146-8, 2009.

25- MIRZA R., ISHAQ S. and AMJAD H.: Transient osteoporosis of the hip. J. Pak. Med. Assoc., Feb., 62 (2): 196-8, 2012.

26- BALAKRISHNAN A., SCHEMITSCH E.H., PEARCE D., et al.: Distinguishing transient osteoporosis of the hip from avascular necrosis. Canadian Journal of Surgery, 46 (3): 187-92, 2003.

27- KARCHEVSKY M., SCHWEITZER M.E., MORRISON W.B., et al.: MRI findings of septic arthritis and associated osteomyelitis in adults. A.J.R. Am. J. Roentgenol., 182 (1): 119-22, 2004.
28- LEARCH T.J. and FAROOKI S.: Magnetic resonance imaging of septic arthritis. Clin. Imaging, 24: 236-42, 2006.

29- SHERWANI P., VIRE A., ANAND R., et al.: Utility of MR Imaging in Developmental Dysplasia of Hip. Austin. J. Radiol., 3 (3): 1052, 2016.

30- EVAN J.Z., EDWARD Y.L., RICARDO R., et al.: Hip Disorders in Children A.J.R., 201: W776-96, 2013.

31- JARAMILLO D., GALEN T.A., WINALSKI C.S., et al.: Legg-Calvé-Perthes disease: MR imaging evaluation during manual positioning of the hip-comparison with conventional arthrography. Radiology, 212: 519-25, 1999.

32- DWEK J.R.: The hip: MR imaging of uniquely pediatric disorders. Magn. Reson. Imaging Clin. N. Am., 17 (3): 509-20, 2009

33- LAHDES V.T., LAMMINEN A., MERIKANTO J., et al.: The value of MRI in early Perthes' disease: An MRI study with a 2-year follow-up. Pediatr. Radiol., 27 (6): 517-22, 1997.

34- MONT M.A., MARULANDA G.A., JONES L.C., et al.: Systematic analysis of classification systems for osteonecrosis of the femoral head. J. Bone Joint Surg. Am. 88 Suppl., 3: 16-26, 2006.

35- STAATZ C., HONNEF D., KOCHS A., et al.: Evaluation of femoral head vascularization in slipped capital femoral epiphysis before and after cannulated screw fixation with use of contrast-enhanced MRI initial results. Eur. Radiol., 17 (1): 163-8, 2007.

36- GREEN D.W., REYNOLDS R.A.K., KHAN S.N., et al.: The Delay in Diagnosis of Slipped Capital Femoral Epiphysis: A Review of 102 Patients. HSS Journal, 1 (1): 103-6, 2005.

37- PROPECK T. and RIDPATH C.A.: Slipped capital femoral epiphysis diagnosed by magnetic resonance imaging. Emergency Radiology, 8: 344-6, 2001.

38- DILLON J.E., CONNOLLY S.A. and CONNOLLY L.P.: MR Imaging of Congenital/Developmental and Acquired Disorders of the Pediatric Hip and Pelvis. Magnetic Resonance Imaging Clinics of North America, 13: 55-80, 2009.

39- ANAND A., RAVIRAJ A. and KODIKAL G.: Subchondral stress fracture of femoral head in a healthy adult. Indian Journal of Orthopaedics, 44 (4): 458-60, 2010.

40- KIMURA T., GOTO T., HAMADA D., et al.: Subchondral Insufficiency Fracture of the Femoral Head Caused by Excessive Lateralization of the Acetabular Rim. Case Reports in Orthopedics, Vol. 2016, Article ID 4371679, $1-5,2016$

41- HIREN P. and ATUL F.K.: Subchondral Insufficiency Fracture of the Femoral Head treated with Core Decompression and Bone Void Filler Support. Arch. Bone Jt. Surg., 4 (3): 264-8, 2016.

42- IKEMURA S., YAMAMOTO T., MOTOMURA G., et al.: MRI evaluation of collapsed femoral heads in patients 60 years old or older: Differentiation of subchondra insufficiency fracture from osteonecrosis of the femoral head. A.J.R. Am. J. Roentgenol., 195 (1): W63-8, 2010. 


\section{دور الرنين المغناطيسى فى تقييم الإصابات غير الورمية لرآس عظمة الفخذ}

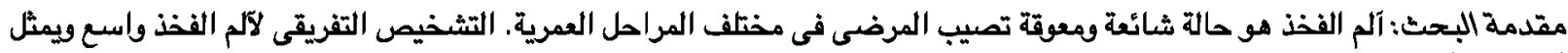

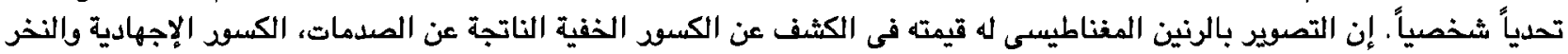
اللاوعائى فى رآس عظمة الفخذ.

آصبح التصوير بالرنين المغناطيسى هو الوسيلة المفضلة لتصوير مرض نخر العظام لآنه فى غاية الحساسية والخصوصية النوعية. يعتبر التصوير بالرنين المغناطيسى طريقة قيمة فى التشخيص المبكر لمرض (ليخ كافيه بيرثيز) آو إكتشافه قبل ظهوره فى الآشعة العادية. كما آنه يوضح مدى إمتداده في المشاشية.

الكسود الخفية فى المرضى كبار السن هى واحدة من العلامات الآكثر شيوعاً والتى تتطلب تصوير مفصل الفخذ بالرنين المغناطيسى وخاصة فى مرضى هشاشئ العظام.

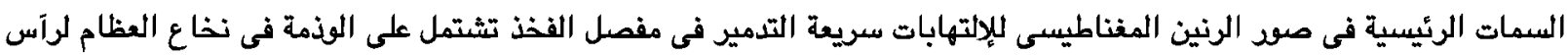

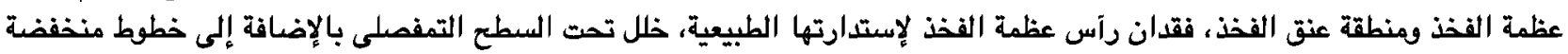
الإثارة بالمشاش.

تعد هشاشة العظام المؤقته فى مفصل الفخذ سبب غير شائع لآلم مفصل الفخذ وتؤثر غالباً على الرجال الآصحاء فى منتصف العمر وآيضاً

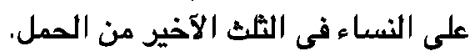

إن التصوير بالرنين المغناطيسى للخلع الخلقى فى الفخذ له العديد من المزايا: فهو غير تداخلى، وغير مؤذى، غير مؤلم، ولا ينطوى على فئى

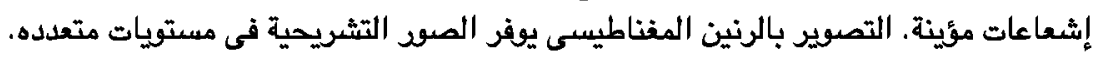
الهدف من البحث: الهدف من هذا العمل هو تقييم دود التصوير بالرنين المغناطيسى فى تشخيص إصابات رآس عظمة الفخذ ما عدا الودميه منها.

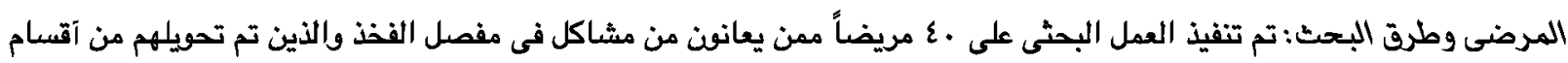

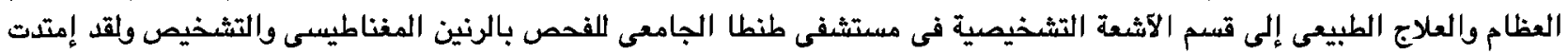

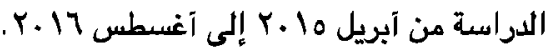

$$
\text { • • القد خصع كل المرضى للآتى على التاريخ المرضى بدقة من المرضى. }
$$

• وسائل التصوير التشخيصية المختلة والتى شملت الآتى: - الآثعة العادية.

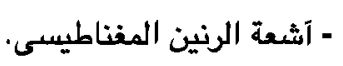

- الموجات فوق الصوتية.

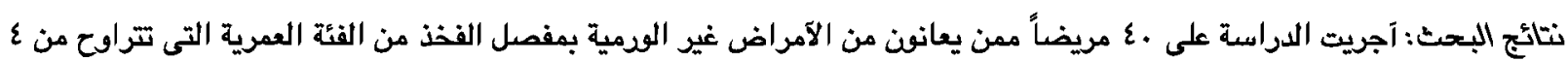

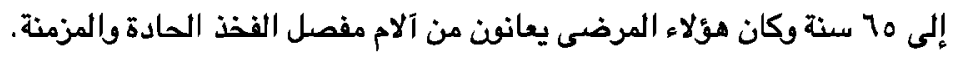

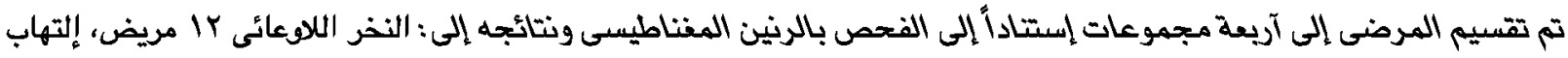

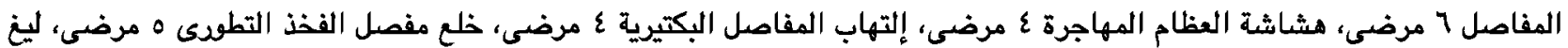

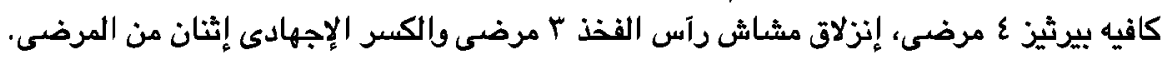

الخلاصة: آن التصوير بالرنين المغناطيسى يجب آن يوصى به فى حالات الإصابات غير الورمية لرآس عظمة الفخذ وهو الوسيلة المفضلة فى التشخيص دون التعرض للإشعاعات المؤينة وعندما تكون الآشعة العادية غير فالانير الاسمة تشخيصياً. 